\title{
ASSOCIATION TEA.M WORK.
}

IKE the devils of Gadarene nativity, the evils which afflict pharmacy are L legion. Sunday work and too many hours of labor on secular days, price cutting and physicians' dispensing, inefficient and insufficient help, fake patent medicines and ovcr-priced proprietaries, cocaine and liquor selling in drug stores, the common indifference of the mass of druggists to association work, educational and legislative problems-these are only a few of the questions with which the pharmaceutical associations must struggle, and as a consequence they have usually been tempted to spread their efforts over too wide a field and to expend their energies upon too great a range of subjects.

This diffusion of energy and consequent loss of cffectiveness is true not only as regards the efforts of the individual societies, but is reflected in the failure of the different societies to act in concert with each other.

As far as the writer has been able to observe, the A. Ph. A. and the N. A. R. D. are in substantial agrecment upon all the great questions which confront pharmacy, but to date there has been a conspicuous lack of "team work" in their efforts to solve these questions. One year the $\mathrm{A}$. $\mathrm{Ph}$. A. makes a special feature of some particular professional or trade evil, and perhaps deals some effective blows upon it, while the N. A. R. D. belabors with equal lustiness some other evil, but is is generally by accident that they both attack the same problem at the same time.

This lack of coordinated effort between these two great national bodies fairly illustrates the relations of the numerous state and local pharmaceutical societies to each other-they profess to be and, in fact, are in sympathy with each other, but they do not pull together, and consequently fail to realize the full effect of collective effort.

That the various organizations have accomplished: a vast amount of good in all the lines of work they have attempted will not be disputed by any candid and unprejudiced observer, but their energies have been so widely diffused in time and space that they have not made the decided impression that would have been made by more concentrated and better directed effort.

In an important sense, perhaps, this general work has not been wasted; it has been a necessary antecedent to the work which is to follow. It has cleared away the tangle of trivialities that obscured the field and has brought the real and vital issues squarely into view; it has developed intelligent sentiment and a common understanding upon a variety of subjects, and has replaced erroneous and hazy ideas by correct and distinct ones. It has been the preliminary skirmishing that has uncovered the nature of the difficulties that must be overcome and has exposed the points upon which the real attacks should be delivered.

It is time now, however, when pharmaceutical organizations should begin to "bunch their hits," and replace their separate efforts by "team work," to stop irregular sniping and try the effect of firing by volleys.

The Journal suggests that at their respective meetings this month the $\mathrm{A}$. $\mathrm{Ph}$. A. and N. A. R. D. select a list of subjects upon which they will cooperate during the next twelvemonth, and that they invite every state and local organization of pharmacists and every individual pharmacist in the country to help carry this joint program to a successful issue.

J. H. BEAL. 